\title{
Establishment of Fashion Clothes Network Virtual Reality Mall
}

\author{
Pingping Meng \\ TSL School of Business and Information Technology \\ Quanzhou Normal University \\ Quanzhou ,China \\ Email: 1981cindy@163.com
}

\begin{abstract}
With the development of computer science and network virtual reality technique, the construction of the network virtual reality mall has come true. Clothes network marketing field puts forward the proposal of constructing the fashion clothes network virtual reality mall. Analyzed and researched establishment of the fashion clothes network virtual reality mall, especially the basic thought of establishment and the six construction of fashion clothes virtual reality mall. Lastly it concluded the B2C solution of the virtual mall.
\end{abstract}

Keywords-virtual reality mall; fashion clothes virtual reality technique; network

\section{VIRTUAL REALITY MALL}

Virtual reality mall is a kind of virtual shopping environment which is based on network and three dimensional technology (short for 3D). By using the B2C e-commerce model, Virtual reality mall enables users to have interactive operation and walk around in the 3D virtual environment. It makes users to be personally on the scene by completely simulating the process of shopping browsing, selection and payment. At the same time, it provides digital management, clear commodity classification, convenient search, perfect financial system and reliable safety system which ensure the effectiveness, integrity and confidentiality of shopping.

\section{FASHION ClOTHES NETWORK VIRTUAL REALITY MALL}

Fashion clothes network virtual reality mall mainly according to the characteristics of fashion clothes, combines the trend of online shopping and the development of emarketing of clothes enterprise. With the characteristics of low cost, easy operation, independent operation, etc, fashion clothes network virtual reality mall provides users who purchase things like fashion clothes with different visual and interactive experience, expanding the integrate platform of clothes network display and marketing. It is developed by using the most advanced three dimensional technology and network multimedia technology. And it is a new kind of mall which integrates with clothes image display, brand navigation and shopping guide and e-commerce. In addition, it integrates resource of garment industry, establishes ecommerce of clothes mall community, and provides the best solution which has complete functions and high price performance ratio for various clothes commercial entities including the shopping center of clothes mall and the specialized market of clothes.

\section{ESTABLISHMENT OF THE FASHION CLOTHES NETWORK VIRTUAL REALITY MALL}

\section{A. The basic thought of establishing the fashion clothes} virtual reality mall

The virtual reality mall provides customers with a vivid and lifelike operating environment in which customers feel like in real mall by playing a role in it. And it can bring the same experience and enjoyment, more perfect and standard service than real mall. The basic thought of establishing fashion clothes virtual reality mall is brought out referring to the basic technologies used in three dimensional virtual reality online games:

- Establish virtual reality scenes. The vivid virtual reality scene is established by using fast virtual system and 360-degree pan-shot; the three dimensional vivid virtual environment is based on the combination of the three dimensional graphic technology, the multi-sense interactive technology and the high resolution technology; and all of the equipment and facilities ( such as shelf, shopping cart, shopping basket, clothes and so on ) can be established dynamically in the mall. Customers are personal on the scene during the process of shopping in the mall.

- Establish virtual characters. Establish different characters of customers and sellers in the fashion clothes virtual reality mall, some of the staffs include sale manager, shopping guide, security staff, usher, deliveryman and so on.

- Establish timely interactive environment. In the virtual reality mall, customers and marketing staffs must communicate timely. The customers' problems can be solved through text, voice and video, etc.

- $\quad$ Establish virtual reality operating environment. The operating environment of customers is of great important since the customers play the most important roles in the virtual reality mall. When a customer chooses a kind of clothes commodity in the virtual mall, they can know the quality of the clothes from various ways such as text, voice, three dimensional image, video even animation and so on. 


\section{B. The six construction of fashion clothes virtual reality mall}

- The combinative construction of $2 D$ plus $3 D$ brings out the greatest advantage. The three dimensional system which is used to establish the fashion clothes network virtual reality mall is incomparable to the two dimensional mall, but the 2D site is irreplaceable on SEO (search engine optimization), easy operation, and the operation habits of some customers. Therefore, The construction of combining $2 D$ and $3 D$ can strengthen the characteristics and advantages of both systems, they combine and complement with each other. System construction is shown in Figure 1.

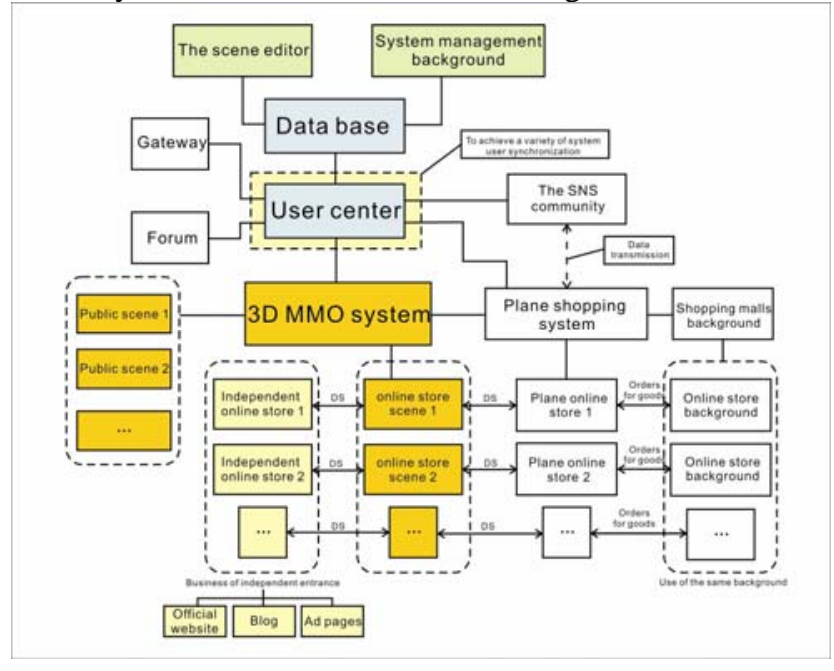

Figure 1. System construction

- Construct the same scale clothes display image as traditional stores. Constructing virtual environment scene by three dimensional technology and rebuilding the construction according to real store reflects the display image of real clothes. The most important thing is that it can show the real details of three dimensional fashion clothes including color, design, fabric and the three dimensional dressing effect.

- Create real clothes marketing atmosphere. It is necessary to create a perfect multiplayer network system for fashion clothes online virtual reality mall. Each user can create a virtual character to represent him or her. People can see each other in the mall and can communicate with each other by various ways such as text, voice and chatting and so on. That constructs the real atmosphere of network clothes commercial marketing.

- Construct various management ways. In the fashion clothes network virtual reality mall, customers can shop and trade like on common shopping websites or use the activity systems inside to do interesting interactive marketing, in that way it attracts consumers to participate or guide offline consumption. Some of the clothes shops can even use the DIY function inside to make customers join in the collocation of clothes commodities which associates with the information of clothes commodities and make the results of DIY into orders.

1. Construction Funds of Master Degree Awarded Unit of Quanzhou Normal University. 2.Fujian university key project construction service routines "The port logistics information platform construction, Haqixi prefecture", Project Number: A103.
Online consumption makes customers fully enjoy the fun of man-machine interaction. There are all kinds of perfect online communication tools set in the fashion clothes network virtual reality mall, which users can have public chat or one-to-one private chat and can have the interactive operation like invite visiting or request the follow of clothes shopping guide while shopping in stores.

- Construct super simulation frames to lead the new fashion shopping era on line. Constructing high simulation clothes mall such as the whole layouts, the street settings, and the design of clothes stores, the displays of brand shop widow even the details of clothes commodities, it can make users enjoy shopping in the fashion clothes mall without going out.

Customers register and login directly via the Internet and establish a role to do shopping on line. It seems like shopping in real clothes mall and customers can feel the atmosphere of fashion. Customers can shop together and have a voice or video chat. In the fashion clothes network virtual reality mall, users can invite their friends to shop together on line. On one hand, it makes friends closer. On the other hand, it saves and transfers various costs to the clothes consumption. The virtual clothes mall system, which provides the function of voice and video chats, promotes the interest and the joy of shopping together and increases the consumption of clothes. During the process of shopping in the mall, the feelings of walking and taking the lift are the same as shopping in real scene. It increases the reality of shopping.

- Construct and strengthen the added value function of navigation and management. During the construction of the fashion clothes network virtual reality mall, the route navigation and the clothes information navigation for users can help them roaming and shopping timely and accurately. Property management is also an important work. In the mall, the work is convenient for the management of property management department, for expressing clear and direct and decreasing the management cost; meanwhile it actually helps the whole facility planning, establishment and management, etc.

\section{The B2C solution of the virtual mall.}

The clothes display in the fashion clothes virtual reality mall including the browsing of the appearance of the clothes from all directions. It can move the real store to the Internet with presentation of three dimensional technology, and also it can simulate the town. In a word, the fashion clothes virtual reality mall puts real mall scenes, streets, store specification to the Internet to establish the clothes virtual shopping center by the combination of three dimensional network technology, online payment technology and so on.

As the realization of online fashion clothes virtual mall, it is not only a simple copy of real mall, but also a membership business platform, basing on the virtual reality technology, which inherits the online information interactive functions of the supply and demand of business opportunity, the clothes display, the merchant management, the online order, etc.

- The functions of the system. Ordinary families can operate the fashion clothes virtual reality mall without 
downloading a client-side since the mall can be operated by implanting IE page. On the IE page, the information of three dimensional scenes don't be affected during the browsing since the information can be downloaded by using dynamic multithreading technology.

In the fashion clothes virtual reality mall, users can register to be the memberships free. Users can choose the characters ( DIY) for themselves after being the memberships and they can walk around in the three dimensional mall with first characters vision. When establishing the characters, users can choose their own nickname, gender, face and hair style, dressing as they like.

- $\quad$ Simulate advertisement in the mall. There is super advertisement system in the fashion clothes virtual reality mall. The mall updates timely the information of fashion clothes, clothes commodity, discount which customers care about, etc. The merchants can sent advertisement massively and have interaction within the limited space of the stores; and they can interact with consumers actively such as introduce the brand and the clothes, chat, greet and do gestures, etc. What's more, the merchants can advertise worldwide and the whole mall can feel the advertisement. For example, the Shengshi net makes store plan and advertises for 3D virtual mall.

- Simulate community of in the mall. In the fashion clothes virtual mall, every user has his/her personal zone. The zone provides the user with independent dressing up and upgrading service. In the community of the mall, the chatting appears the same way in 3D online game and it's natural for users to have text chatting under the three dimensional scene. Not only text chatting, users can also have real-time voice chatting even video chatting which allow many users to interact with each other and join in game together. The chatting of the users, merchant and customers in trades will be stored in time for them to use.

In the community, users can have real-time interaction such as transfer action and touch. The characters have simple gestures such as walking, running, jumping and intimate behaviors like hug, kiss between couples. During the clothes business process, the shopping guides and the clerks can establish online three dimensional characters in their stores. The fashion clothes buyers can interact with merchants on line by touch with word, expression, action, voice and video. It realizes real sale.

- $\quad$ The search of the stores and the clothes brand. As for the network users, the most important thing is to be able to know stores' positions and the users themselves' route location at any time. In the mall, each store and each brand have their numbers. Users can get the information about the three -dimensional position of the stores and the clothes brands by inputting corresponding numbers and parameters. As the results come out, the corresponding three-dimensional positioning will be done. The hot positioning of the navigation chart directly reflects the layout and the distribution of the clothes stores and brands in the town. Through inputting the number of the stores or the name of the clothes brands, the users can have three-dimensional position directly and then enter the stores by triggering the hot positioning of the navigation chart.

- The purchase and the online payment. In the fashion clothes virtual reality mall, customers can enter the three dimensional mall after register and character establishment. According to the customers' own understanding or the introduction and the note of the system, the customers can enter the corresponding stores to try on and choose clothes. They can choose shopping carts or baskets by themselves to buy their favorite clothes after trying on. And they can interact with clothes shopping guide to know more about the clothes as well. After the customers choosing their clothes, they can go to the checkout counter and communicate with the cashier then to pay on line. The merchants will deliver goods timely according to the process after the payment.

The merchants of the fashion clothes network virtual reality mall will manage the delivery of the goods that have been sold. According to the quantity, price, address, the merchants will choose the most quick logistics and deliver timely. At the same time, they manage to makes sure that the customers can receive the good timely and safely.

- The management of the client, the reputation, the supervision and the customer service. In the fashion clothes virtual reality mall, the consumers have to get users' information acquisition and check when they register, login, logout, order and choose the characters of themselves for shopping in the community of the mall. As for the sellers of the mall, there are corresponding management of their login, the design of the stores, the clothes display, human-based management of the clothes and the logout as well.

After the customers buying clothes in the mall, the clothes merchants will get credits (namely growth of the characters) after the customers assessing them. There are different stages of management according to the credits and the stages which will be marked by special symbols and dressing states; and the same management produces while the merchants selling clothes in the mall and the customers will get credits after the merchants assessing them.

The supervisions of the mall include the inspection and management of the illegal stores, the inspection and management of the products on shelf, the supervision of the advertisement and the interactive content, the resolution of the complaint and report.

The customer service provides consults and the service to all kinds of everyday problems in the mall and it replies, reports and gives feedback timely to the problems. The customers can contact with it whenever they have problems during shopping in the fashion clothes virtual reality mall.

\section{CONCLUSION}

At present, There are several technical problems when combining the fashion clothes virtual reality mall with the present e-commerce system, such as the cost of the hardware equipment is relatively high. However, with the development and improvement of the virtual reality technology and the three dimensional technology, the three dimensional technology has closely connected with human life. As the clothes network shopping market is more and more mature in 
various countries, the fashion clothes virtual reality mall which combines with the characteristics of fashion clothes will definitely be the trend of the clothes network ecommerce in the future. To a great extend, the establishment and the popularity of the fashion clothes virtual reality mall will strengthen the competitiveness of the clothes enterprise meanwhile greatly promote the development and prosperity of the clothes industry.

\section{REFERENCES}

[1] Smith. James E, Nain Ravi and Nair Ravi, Virtual Machines. Elsevier Science Ltd, Jul.2005.

[2] Y. M. Zhao, S. M. Wu and Z. G. Pan, "Design and implementation of online 3D virtual mall," Journal of system simulation, Jul.2003, p 980-982.

[3] W. H. Xie and L. R. Ye, "Explore the establishment of virtual reality mall”, Electronic Commerce, Mar.2006, p53-54 